\title{
The highly rearranged karyotype of the hangingfly Bittacus sinicus (Mecoptera, Bittacidae): the lowest chromosome number in the order
}

\author{
Ying Miao', Bao-Zhen $\mathrm{Hua}^{2}$ \\ I College of Life Sciences, Northwest A\&F University, Yangling, Shaanxi 712100, China 2 College of Plant \\ Protection, Northwest A\& F University, Yangling, Shaanxi 712100, China \\ Corresponding author: Bao-Zhen Hua (huabzh@nwafu.edu.cn)
}

Academic editor: V. Lukhtanov | Received 22 April 2020 | Accepted 4 July 2020 | Published 30 July 2020

http://zoobank.org/885B5AE8-3F19-42C1-86C5-904DDD26CF55

Citation: Miao Y, Hua B-Z (2020) The highly rearranged karyotype of the hangingfly Bittacus sinicus (Mecoptera, Bittacidae): the lowest chromosome number in the order. Comparative Cytogenetics 14(3): 353-367. https://doi. org/10.3897/CompCytogen.v14i3.53533

\begin{abstract}
Cytogenetic features of the hangingfly Bittacus sinicus Issiki, 1931 were investigated for the first time using C-banding and DAPI (4',6-diamidino-2-phenylindole) staining. The karyotype analyses show that the male $B$. sinicus possesses the lowest chromosome number $(2 n=15)$ ever observed in Mecoptera, and an almost symmetric karyotype with $M_{C A}$ (Mean Centromeric Asymmetry) of 12.55 and $C V_{C L}$ (Coefficient of Variation of Chromosome Length) of 19.78. The chromosomes are either metacentric or submetacentric with their sizes decreasing gradually. Both the C-banding and $\mathrm{DAPI}^{+}$patterns detect intermediate heterochromatin on the pachytene bivalents of $B$. sinicus, definitely different from the heterochromatic segment at one bivalent terminal of other bittacids studied previously. The male meiosis of B. sinicus is chiasmate with two chiasmata in metacentric bivalents and one in the submetacentric bivalent. The sex determination mechanism is $\mathrm{X} 0(\hat{\jmath})$, which is likely plesiomorphic in Bittacidae. Two alternative scenarios of karyotype origin and evolution in Bittacus Latreille, 1805 are discussed.
\end{abstract}

\section{Keywords}

C-banding technique, chromosome rearrangement, cytogenetics, DAPI, evolution, Holometabola, meiosis 


\section{Introduction}

Bittacidae is the second largest family of Mecoptera, and currently consists of over 200 species in 18 genera in the world (Zhang et al. 2020). The adults of Bittacidae comprise an exclusive group that possesses three pairs of elongated raptorial legs with a single claw at pretarsus and adopts a predacious feeding strategy (Bornemissza 1966; Byers and Thornhill 1983; Penny 2006; Tan and Hua 2008; Ma et al. 2014). They are commonly known as hangingflies because between flights they are unable to stand on a surface but hang themselves from the edges of leaves or twigs using the prehensile foretarsi (Thornhill 1977; Tan and Hua 2008). Bittacus Latreille, 1805 is the largest and most widespread genus of Bittacidae, and comprises more than $2 / 3$ species of the family recorded from all zoogeographical regions (Penny and Byers 1979). Owing to considerable morphological variations (Lambkin 1988; Chen et al. 2013) and complicated distribution patterns (Penny 1975; Li and Ren 2009), the evolutionary relationship within this genus remains largely unknown to date.

Chromosomes of eukaryotic organisms may carry crucial information related to the species diversification and evolution (Gokhman and Kuznetsova 2006; Noor et al. 2007; Faria and Navarro 2010). The variations of chromosome number reflect the result of complicated chromosomal rearrangements and may help reveal the evolutionary relationships of sibling species (White 1974; Lukhtanov et al. 2005; Kandul et al. 2007; Faria and Navarro 2010). The chromosomal morphology may provide substantial information related to structural rearrangements, which may contribute to the increased level of divergence among taxa (Rieseberg and Burke 2001; Navarro and Barton 2003; Butlin 2005). Such studies have been well documented in many insect groups, including aquatic bugs (Stoianova et al. 2020), psyllids (Nokkala et al. 2019), bush crickets (Kociński et al. 2018), beetles (Dutrillaux and Dutrillaux 2019), butterflies (Dincă et al. 2011), warrior wasps (Menezes et al. 2019), and ants (Pereira et al. 2018). In Bittacidae, however, the cytogenetic information is poorly documented, with only six species reported to date (Matthey 1950; Atchley and Jackson 1970; Miao and Hua 2017, 2019).

According to the limited cytogenetic data available, the chromosome number varies extensively in Bittacidae (Matthey 1950; Atchley and Jackson 1970; Miao and Hua 2017, 2019). It is $2 n=25$ in B. italicus (Müller, 1766), $2 n=27$ in $B$. flavidus Huang et Hua, 2005, $2 n=29$ in B. pilicornis Westwood, 1846, $2 n=31$ in B. stigmaterus Say, $1823,2 n=35$ in B. planus Cheng, 1949, and $2 n=41$ in Terrobittacus implicatus (Huang et Hua in Cai et al., 2006). Each species examined has a distinctive karyotype, which represents an important diagnostic feature in Bittacidae and provides useful information on the evolutionary relationship of Mecoptera (Miao and Hua 2017, 2019).

In this paper, we present for the first time information on the karyotype and male meiosis of the hangingfly Bittacus sinicus Issiki, 1931, attempting to enrich our knowledge of the chromosome evolution of Bittacus and to contribute to the cytogenetic data for a better understanding of the evolutionary history of Bittacidae. 


\section{Materials and methods}

\section{Adult collecting}

Adults of B. sinicus (Fig. 1A) were collected from Shimian County $\left(29^{\circ} 03^{\prime} 00^{\prime \prime N}\right.$, $102^{\circ} 21^{\prime} 00 " E$, elev. 1800-1890 m), Sichuan Province in China from July to August in 2016 and Paomashan (3002'36"N, 101'57'33"E, elev. 2600 m), Sichuan Province in China in late July 2018, respectively.

\section{Insect rearing}

Live adults were reared in screen-wired cages $(40 \times 60 \times 60 \mathrm{~cm})$ containing twigs and leaves of plants and moist absorbent cotton (Miao and Hua 2019). Eggs, larvae and pupae were incubated and reared in plastic containers with humid humus. Live flies and frozen pupae of Musca domestica Linnaeus, 1758 (Diptera, Muscidae) were provided as food for the adults and larvae, respectively. Temperature was kept at $16 \pm$ $2{ }^{\circ} \mathrm{C}$ for larvae, $21 \pm 2{ }^{\circ} \mathrm{C}$ for pupae, and $23 \pm 2{ }^{\circ} \mathrm{C}$ for adults. Relative humidity was maintained at $75 \% \pm 10 \%$ (Miao and Hua 2017).

\section{Cytogenetic analyses}

Chromosome spreads were prepared using the testes of larvae and pupae following Imai et al. (1988). The mitotic metaphase and early stages of meiosis were obtained from males of the third and fourth (last) instar larvae, and the male meiosis I/II mainly from young pupae. Totally 66 larvae (46 from Shimian County and 20 from Paomashan) and 12 pupae (nine from Shimian County and three from Paomashan) of $B$. sinicus were used for chromosome preparations.

C-banding was obtained using the same technique as in Miao and Hua (2019). The fluorochrome DAPI (4',6-diamidino-2-phenylindole) staining was performed to characterize the $\mathrm{DAPI}^{+}$heterochromatin (the shiny blue regions rich in AT bases) on chromosomes, following Rebagliati et al. (2003).

Photographs were taken with a Nikon DS-Fil digital camera mounted on a Nikon Eclipse 80i microscope (Nikon, Tokyo, Japan). The fluorescence signals were observed with a UV filter $(330-385 \mathrm{~nm})$.

\section{Statistical analyses}

Five spermatogonial cells with well-spread chromosomes at mitotic metaphase were used to statistically analyze the chromosomes of B. sinicus following the procedures of Miao and Hua (2017). The captured images were quantified using the NIS-Element 
D 3.22 software (Nikon, Tokyo, Japan). The chromosomal morphology was determined based on the arm ratio where chromosomes were classified as metacentric $(\mathrm{m})$, submetacentric (sm), subtelocentric (st), or telocentric (t) (Levan et al. 1964). The following features of chromosomes were measured: absolute chromosome length $(A L)$, long arm length $(L)$, short arm length $(S)$, arm ratio $(r=L / S)$, centromeric index $(i=$ $S \times 100 / A L)$, and relative chromosome length $(R L)$ of each chromosome $(R L=A L \times$ $\left.100 / \sum A L\right)$. The evaluated data are presented as mean $\pm \mathrm{SD}$.

The karyotype asymmetry is represented by two components, the heterogeneous degree of chromosome lengths (interchromosomal asymmetry) and the prevalence of telo-/ subtelocentric chromosomes (intrachromosomal asymmetry) (Astuti et al. 2017). Two separate parameters were assessed, i.e. Coefficient of Variation of Chromosome Length $\left(C V_{C L}\right)$ (Paszko 2006) and Mean Centromeric Asymmetry $\left(M_{C A}\right)$ (Peruzzi and Eroğlu 2013).

\section{Results}

\section{Karyology}

The males of $B$. sinicus possess $2 n=15$ (Fundamental Number $F N=30$ ), with the karyotype formula of $13 \mathrm{~m}+2 \mathrm{sm}$ (Fig. 1B, C).

The $A L$ ranges from $7.47 \pm 0.26$ to $3.72 \pm 0.05 \mu \mathrm{m}$, and the $R L$ from $8.43 \pm 0.29$ to $4.20 \pm 0.05$. Autosomal bivalents decrease gradually in size, and the sex chromosome $(\mathrm{X})$ is the smallest of the set. The total length of all chromosomes is $88.65 \mu \mathrm{m}$ (Table 1 ).

Table I. Morphometric analyses of the chromosomes of Bittacus sinicus based on five spermatogonial cells from a male larva.

\begin{tabular}{lcccccccc}
\hline Pair No. & $\boldsymbol{A} \boldsymbol{L} \pm \mathbf{S D}(\boldsymbol{\mu m})$ & $\boldsymbol{R} \boldsymbol{L} \pm \mathbf{S D}$ & $\boldsymbol{L} \pm \mathbf{S D}(\boldsymbol{\mu m})$ & $\boldsymbol{S} \pm \mathbf{S D}(\boldsymbol{\mu m})$ & $(\boldsymbol{L}-\boldsymbol{S}) /(\boldsymbol{L}+\boldsymbol{S})$ & $\boldsymbol{i}$ & $\boldsymbol{r}$ & Type \\
\hline 1 & $3.98 \pm 0.06$ & $4.49 \pm 0.07$ & $2.62 \pm 0.05$ & $1.36 \pm 0.18$ & 0.32 & 34.11 & 1.93 & $\mathrm{sm}$ \\
& $4.29 \pm 0.02$ & $4.83 \pm 0.03$ & $2.75 \pm 0.03$ & $1.53 \pm 0.02$ & 0.29 & 35.74 & 1.80 & $\mathrm{sm}$ \\
2 & $4.97 \pm 0.24$ & $5.61 \pm 0.27$ & $2.67 \pm 0.10$ & $2.30 \pm 0.10$ & 0.07 & 46.27 & 1.16 & $\mathrm{~m}$ \\
& $5.38 \pm 0.04$ & $6.07 \pm 0.05$ & $3.18 \pm 0.22$ & $2.20 \pm 0.15$ & 0.18 & 40.84 & 1.45 & $\mathrm{~m}$ \\
3 & $6.00 \pm 0.17$ & $6.77 \pm 0.19$ & $3.45 \pm 0.05$ & $2.55 \pm 0.12$ & 0.15 & 42.55 & 1.35 & $\mathrm{~m}$ \\
& $6.12 \pm 0.08$ & $6.90 \pm 0.09$ & $3.35 \pm 0.03$ & $2.76 \pm 0.06$ & 0.10 & 45.19 & 1.21 & $\mathrm{~m}$ \\
4 & $6.45 \pm 0.08$ & $7.27 \pm 0.09$ & $3.48 \pm 0.05$ & $2.97 \pm 0.12$ & 0.08 & 46.00 & 1.17 & $\mathrm{~m}$ \\
& $6.50 \pm 0.21$ & $7.33 \pm 0.24$ & $3.68 \pm 0.22$ & $2.83 \pm 0.13$ & 0.13 & 43.45 & 1.30 & $\mathrm{~m}$ \\
5 & $6.59 \pm 0.15$ & $7.44 \pm 0.17$ & $3.49 \pm 0.13$ & $3.10 \pm 0.29$ & 0.06 & 47.08 & 1.12 & $\mathrm{~m}$ \\
& $6.60 \pm 0.15$ & $7.44 \pm 0.17$ & $3.49 \pm 0.11$ & $3.11 \pm 0.20$ & 0.06 & 47.16 & 1.12 & $\mathrm{~m}$ \\
6 & $6.92 \pm 0.64$ & $7.80 \pm 0.72$ & $3.93 \pm 0.09$ & $2.99 \pm 0.12$ & 0.14 & 43.18 & 1.32 & $\mathrm{~m}$ \\
& $6.62 \pm 0.61$ & $7.46 \pm 0.69$ & $3.56 \pm 0.26$ & $3.05 \pm 0.17$ & 0.08 & 46.14 & 1.17 & $\mathrm{~m}$ \\
7 & $7.04 \pm 0.11$ & $7.94 \pm 0.12$ & $3.92 \pm 0.09$ & $3.12 \pm 0.01$ & 0.11 & 44.31 & 1.26 & $\mathrm{~m}$ \\
& $7.47 \pm 0.26$ & $8.43 \pm 0.29$ & $3.97 \pm 0.26$ & $3.50 \pm 0.25$ & 0.06 & 46.90 & 1.13 & $\mathrm{~m}$ \\
& $3.72 \pm 0.05$ & $4.20 \pm 0.05$ & $1.98 \pm 0.13$ & $1.75 \pm 0.09$ & 0.06 & 46.94 & 1.13 & $\mathrm{~m}$ \\
\hline
\end{tabular}

Notes: $A L$, absolute chromosome length (actual length of chromosomes); $R L$, relative chromosome length $(R L=A L /$ total length of the chromosome complement); $\mathrm{SD}=$ standard deviation; $L$, long arm length; $S$, short arm length; $i$, centromeric index $(i=s \times 100 / A L)$; $r$, arm ratio $(r=L / S)$; m, metacentric; sm, submetacentric. 

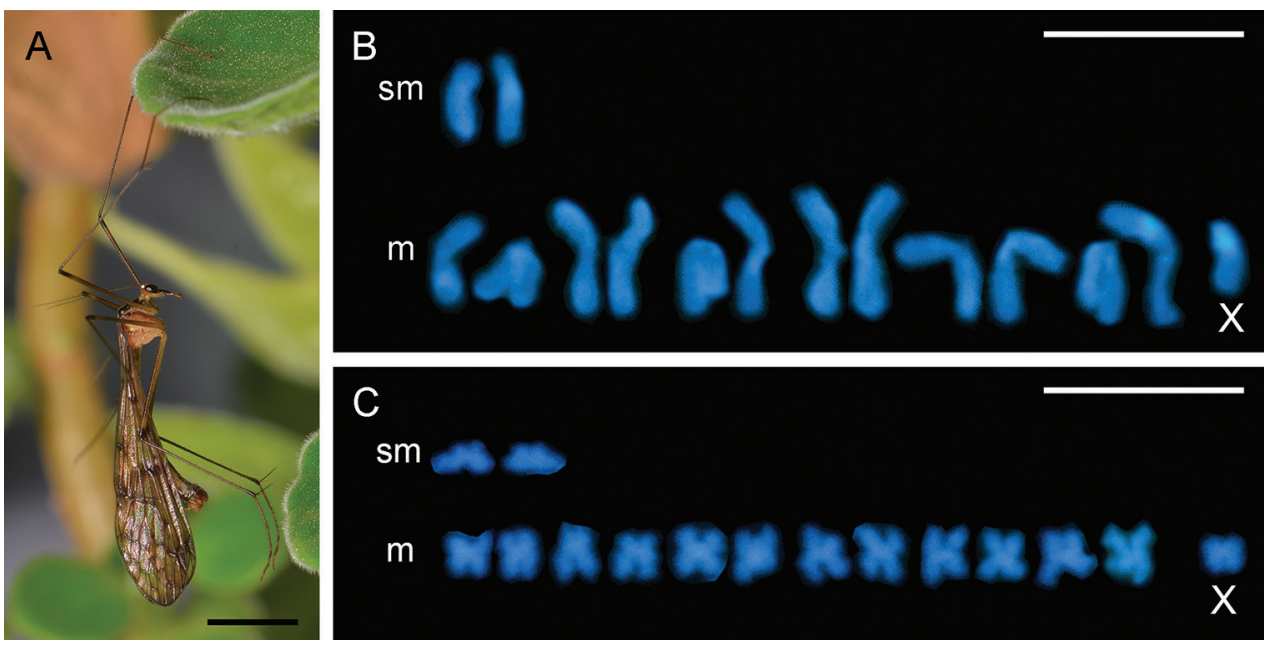

Figure 1. Karyotypes of Bittacus sinicus with DAPI staining A habitus of male adult B spermatogonial metaphase $\mathbf{C}$ meiotic anaphase I. Abbreviations: $\mathrm{m}$, metacentric; sm, submetacentric; $\mathrm{X}$, sex chromosome. Scale bars: $5 \mathrm{~mm}(\mathbf{A}) ; 10 \mu \mathrm{m}(\mathbf{B}, \mathbf{C})$.

The $M_{C A}$ is calculated as 12.55 and the $C V_{C L}$ is 19.78 . The relatively low degrees of both intrachromosomal and interchromosomal asymmetries indicate that the karyotype of $B$. sinicus is almost symmetric.

\section{Banding patterns}

Conspicuous heterochromatin was observed on the meiotic bivalents of B. sinicus after C-banding and DAPI staining (Fig. 2). Both treatments reveal that the autosomal bivalents exhibit intermediate heterochromatin. The sex chromosome is heteropycnotic and totally heterochromatic at the early pachytene (Fig. 2A, C), but becomes isopycnic with two heterochromatic dots later (Fig. 2B, D).

\section{Chiasmate male meiosis}

The synaptic attraction between the homologues terminates from the pachytene to diplotene. The early diplotene appears to be the diffuse stage, which can be interpreted as uncondensed bivalents connected by chiasmata (Fig. 3A). During this stage, the intermediate region of the bivalents is heavily stained and arranged dispersedly, while the remaining bivalents are weakly stained and are often overlooked consequently. The chromosomes move apart in repulsion and are held together only at exchange points, which appear as visible chiasmata in the diplotene stage (Fig. 3B). Metacentric bivalents exhibit two terminal chiasmata and look like large rings, whereas the submetacentric one usually 

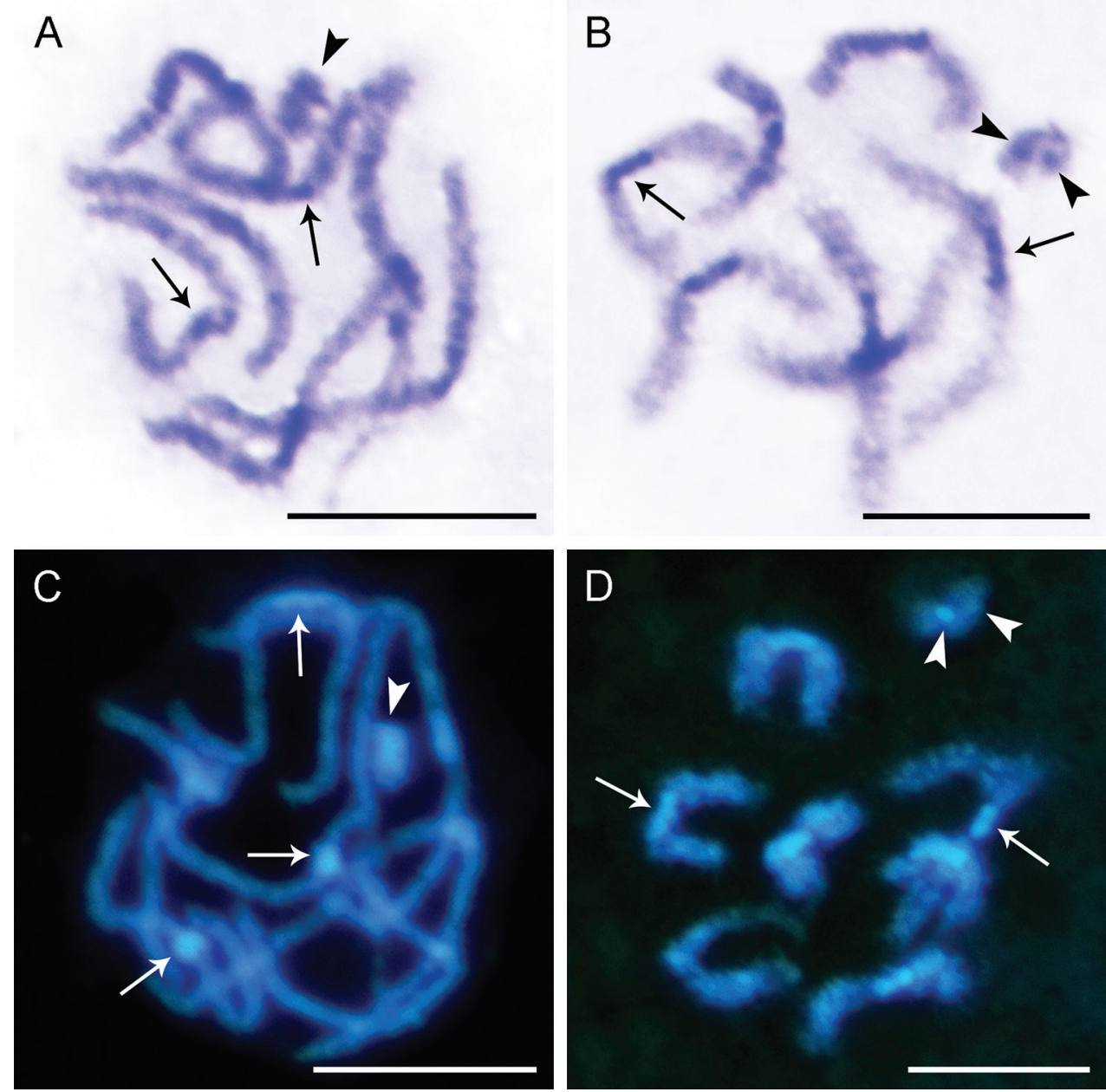

Figure 2. Pachytene bivalents of Bittacus sinicus, stained with C-banding (A, B) and DAPI (C, D) A, C early pachytene, showing the intermediate heterochromatin on bivalents and the heteropycnotic sex chromosome (arrowhead) B, D late pachytene, showing the sex chromosome with a dot-shaped heterochromatic block (arrowheads). Arrows point to the intermediate heterochromatin. Scale bars: $10 \mu \mathrm{m}$.

contains only one terminal chiasma at the long-arm side as a long rod-shape. Chiasmata can be clearly visible after some condensation of the chromosomes at diakinesis (Fig. 3C). In B. sinicus the mean chiasma count per cell was 13.2 (50 cells, ranging from 13 to 14).

Bivalents assemble at the equatorial plate in metaphase I (Fig. 3D) and become oriented with their centromeres poleward (Fig. 3E). In B. sinicus the rod-shaped bivalent is bound by one chiasma at one arm end (asterisk in Fig. 3F), whereas the ring-shaped bivalents have both arms bound by chiasmata. The autosomal bivalents separate into dyads, whereas the X univalent moves undividedly to one pole (Fig. 3G-I), indicating that B. sinicus has the initial-/prereductional meiosis. Each dyad consists of two divergent chromatids associated only in the regions proximal to the centromere (Fig. 3G, 

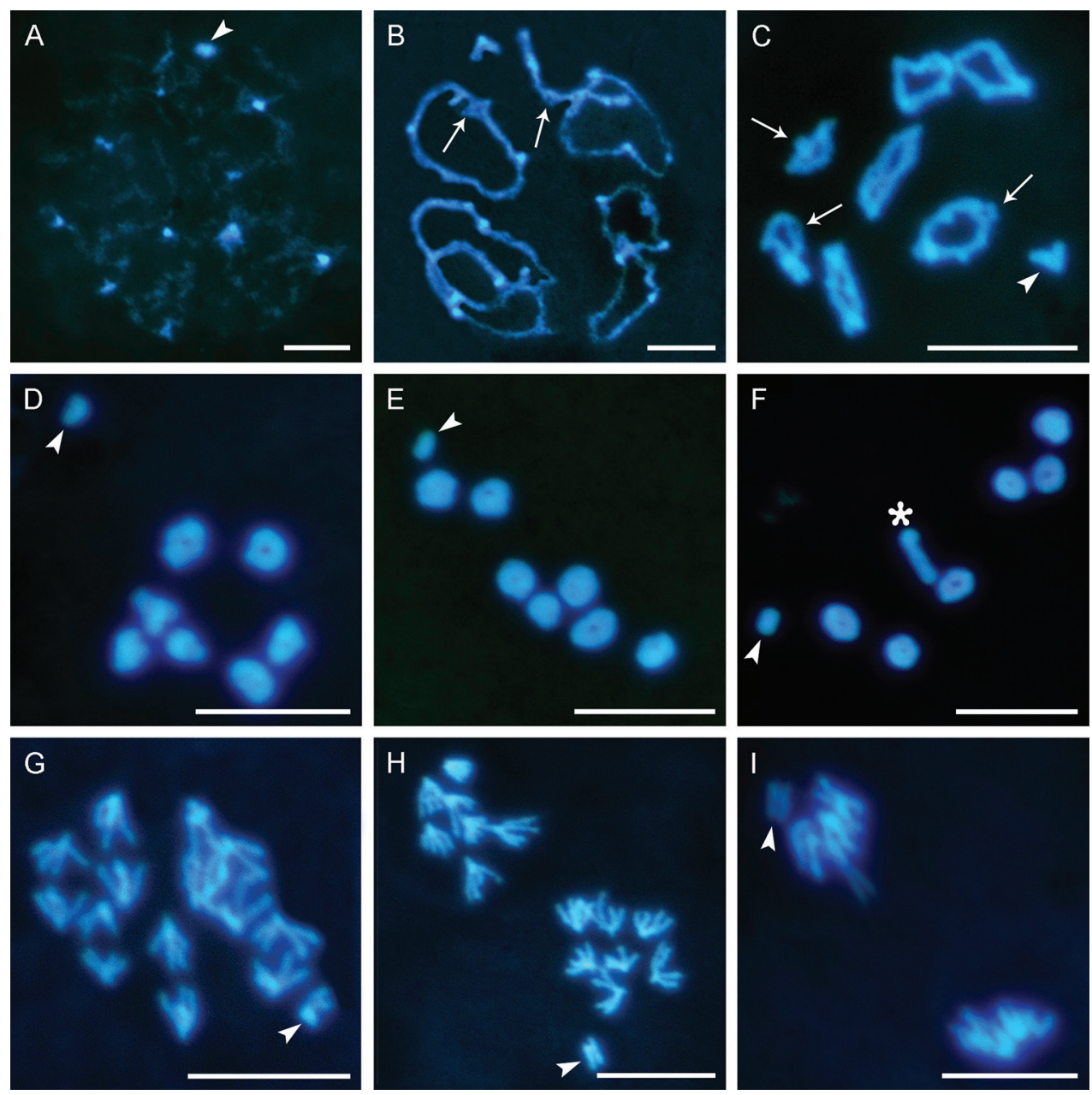

Figure 3. Meiosis I of Bittacus sinicus $\mathbf{A}$ diffuse diplotene with the condensed sex chromosome and decondensed bivalents B diplotene, showing the bivalents are held together only at exchange points (arrows) C diakinesis, showing the evident chiasmata (arrows) D bivalents assembling at the equatorial plate in metaphase I (polar view) E, F metaphase I in side view, showing the ring-shaped bivalents with two chiasmata and rod-shaped bivalent with one terminal chiasma (asterisk) $\mathbf{G}$ anaphase disjunction, showing the divided bivalents and the undivided sex chromosome $\mathbf{H}$ anaphase I, showing the chromosome number of $B$. sinicus is $2 n=15 \mathbf{I}$ telophase I. Arrowheads show the sex chromosome. Scale bars: $10 \mu \mathrm{m}$.

H). Both submetacentric and metacentric dyads are four armed with a double V-shape in anaphase I. The dyads reach the opposite poles and fuse into an indistinguishable mass of chromatin in telophase I (Fig. 3I).

Meiosis II takes place immediately after the first meiotic division. The movement of the X univalent toward only one pole at anaphase I leads to the formation of two classes of nuclei (Fig. 4A, B). The sister chromatids of each dyad are widely splayed, but are held together at the centromere in prometaphase II (Fig. 4C). The centromeric 

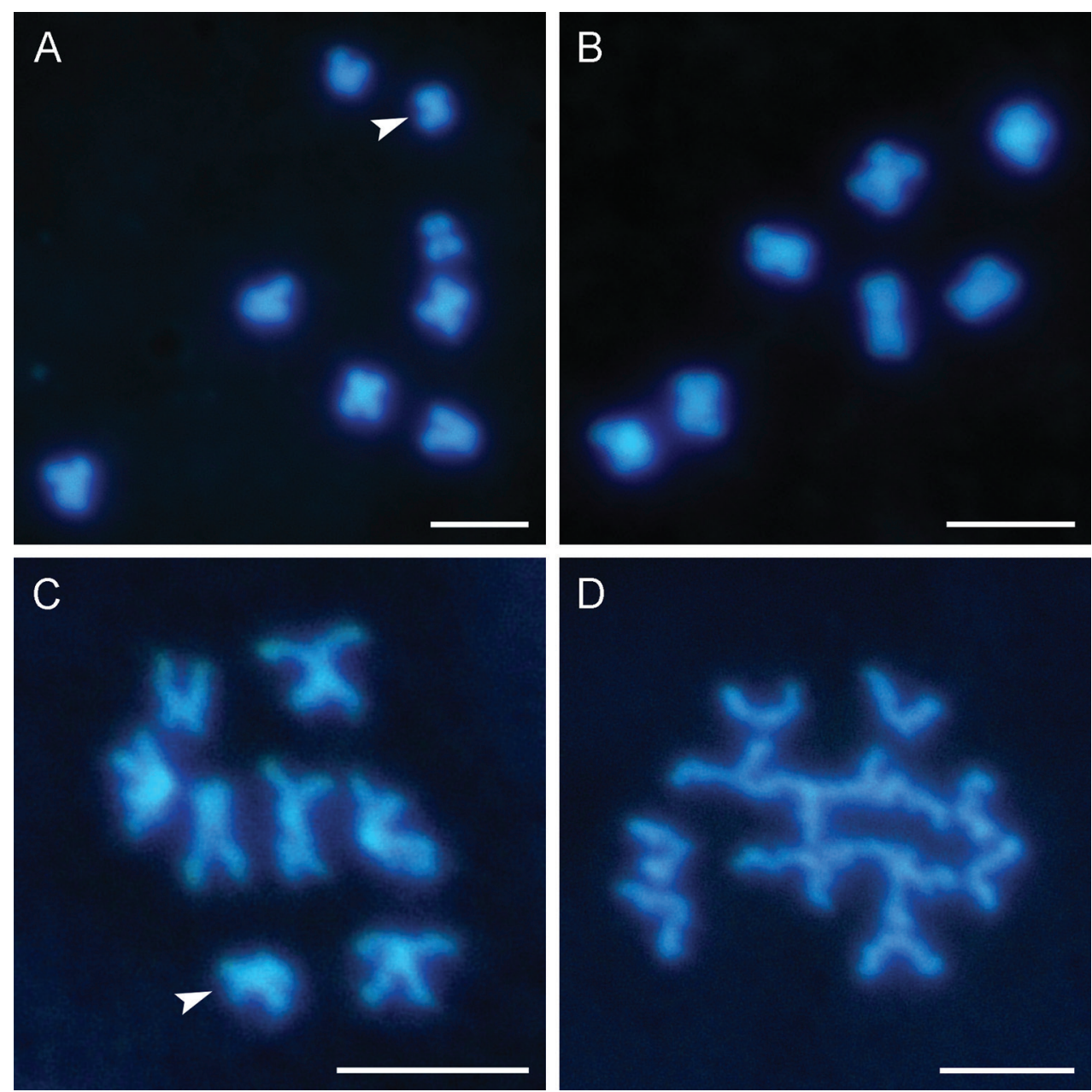

Figure 4. Meiosis II of Bittacus sinicus A, B the secondary spermatocytes: A with $n=8$ B with $n=7$ C prometaphase II, showing the striking repulsion between the sister chromatids of each dyad chromosome $\mathbf{D}$ anaphase II, showing the separation of sister chromatids. Arrowheads show the sex chromosome. Scale bars: $5 \mu \mathrm{m}$.

cohesion between the two sister chromatids is removed in anaphase II, and the sister chromatids are pulled apart by microtubules attached to the kinetochore (Fig. 4D).

\section{Sex chromosome system}

The diploid somatic chromosome number $(2 n)$ is reduced to the haploid gametic chromosome number $(n)$ during the first meiosis. Both the autosomes and the sex chromosome exhibit pre-reductional type of meiosis. The haploid chromosome numbers are different between the two daughter nuclei with $n=7+\mathrm{X}$ (Fig. 4A) and $n=7$ (Fig. 4B), indicating an X0 sex system of the male $B$. sinicus. 


\section{Discussion}

The present study is the first attempt to investigate the karyotype and male meiosis of $B$. sinicus. As in other bittacids studied previously, B. sinicus has the chiasmate meiosis and the $\mathrm{X} 0(\widehat{)})$ sex determination mechanism, which are likely the plesiomorphies in Bittacidae (Matthey 1950; Atchley and Jackson 1970; Miao and Hua 2017, 2019).

Bittacus sinicus has the lowest chromosome number $2 n=15$ ever observed in Mecoptera. Previously, $2 n=17$ chromosomes recorded for Nannochorista dipteroides Tillyard, 1917 (Nannochoristidae) was considered the lowest number reported for this order (Bush 1966). Despite limited chromosome data available, the chromosome number exhibits considerable variations among the families of Mecoptera, from $2 n=15$ to 41 in Bittacidae, $2 n=19$ to 31 in Boreidae (Cooper 1951, 1974), 2n= 17 to 27 in Nannochoristidae (Bush 1966), and $2 n=35$ to 47 in Panorpidae (Naville and Beaumont 1934; Ullerich 1961; Atchley and Jackson 1970; Xu et al. 2013; Miao et al. 2017, 2019).

In Bittacidae, each species examined has a distinctive karyotype, and the two genera (Bittacus and Terrobittacus Tan et Hua, 2009) investigated are distinguishable cytogenetically. Bittacus has relatively low chromosome numbers and symmetric karyotypes, while Terrobittacus has a higher chromosome number and less symmetric karyotype (Miao and Hua 2017), suggesting that the chromosomal changes may have participated in the lineage differentiation of Bittacidae.

Interestingly, the sex chromosome is the smallest element in the karyotype of B. sinicus, but is larger than the majority of autosomes in other bittacids studied (Miao and Hua 2017, 2019). Therefore, we speculate that autosome-autosome fusions may contribute to the karyotype formation in B. sinicus. Similar rearrangements are also suggested for some recently differentiated species of the scorpionflies Panorpidae (Miao et al. 2019). A notable example is Neopanorpa lipingensis Cai et Hua, 2009, which has a distinct chromosome number of $2 n=33$, not $2 n=41$ found in most members of Neopanorpa van der Weele, 1909 , indicating that fusion events occurred at least eight times among the autosomes.

The C-banding pattern of B. sinicus is represented by intermediate blocks on pachytene bivalents and is definitely different from the heterochromatic segment at one bivalent terminal in other bittacids (Atchley and Jackson 1970; Miao and Hua 2017, 2019), implying that inversions may participate in the changes of chromosome morphology.

Conspicuous bands are detectable on pachytene bivalents using the DAPI staining. In general, the terminal DAPI (AT-rich) heterochromatin at one side of a bivalent is the most frequent pattern, which has been observed in the majority of Panorpidae and Bittacidae investigated (Miao and Hua 2017, 2019; Miao et al. 2019). In B. sinicus, however, the DAPI ${ }^{+}$bands are present in the intermediate regions of all bivalents (Fig. $2 \mathrm{C}$, D). Bivalents with intermediate $\mathrm{DAPI}^{+}$heterochromatin were also found in the species of Neopanorpa and were considered as important evidence for the evolutionary reduction of chromosome number in Panorpidae (Miao et al. 2019).

Two alternative hypotheses (fission and fusion) can explain the karyotype formation in the genus Bittacus. The fission hypothesis assumes that the cytogenetic features of $B$. sinicus are primitive with a low chromosome number, relatively large autosomes and reduced heterochromatin. The karyotype changes of Bittacus (Miao and Hua 
2017, 2019) are similar to those of ants and wasps, in which the centric fissions tend to increase the chromosome number and accumulate chromatin (mainly heterochromatin) (Imai et al. 1986, 1994, 2001).

Alternatively, the fusion hypothesis may also explain the karyotype variations found in Bittacus. The karyotype of B. sinicus is considered the derived condition and is shaped by Robertsonian translocations of acrocentric chromosomes and/or reciprocal translocations between meta-/submetacentric and acrocentric ones, which are generated by pericentric inversions. During the translocation events, small centromeric chromosomes (in addition to the final fused chromosomes) may be produced and lost within a few cell cycles. Such scenarios may explain the elimination of centromeres and heterochromatin toward the $B$. sinicus karyotype, and has been suggested for many monocentric organisms, such as the plant Arabidopsis thaliana (Linnaeus, 1758) (Lysak et al. 2006), the flatworm Aspidogaster limacoides Diesing, 1834 (Bombarová et al. 2015), the pangolin Manis javanica (Desmarest, 1822) (Nie et al. 2009), the mouse Akodon Meyen, 1833 (Ventura et al. 2009), the grasshopper Ronderosia Cigliano, 1997 (Orthoptera, Acrididae) (Castillo et al. 2019), the beetle Dichotomius Hope, 1838 (Coleoptera, Scarabaeidae) (Cabral-de-Mello et al. 2011), and the ants Myrmicinae (Cardoso et al. 2014). Based on the phylogeny of the Chinese Bittacidae (YM, unpublished data), we speculate that the cytogenetic features observed in $B$. sinicus may be derived conditions, including the low number of chromosomes, relatively large sizes of autosomes and the intermediate distribution of heterochromatin.

Chromosome rearrangements are proposed as an important driving force of diversification since they lead to speciation via formation of reproductive incompatibility or recombination suppression (Navarro and Barton 2003; Ayala and Coluzzi 2005; Butlin 2005; Kandul et al. 2007; Brown and O'Neill 2010; Kirkpatrick 2010; Mills and Cook 2014). According to the models of chromosomal speciation, there is an increasing level of divergence near rearrangement breakpoints, which tend to accumulate alleles involved in the reproductive isolation (Coghlan et al. 2005; Faria and Navarro 2010). In Bittacus, the cytogenetic data available indicate that the chromosomal evolution involves progressive changes in chromosome number and karyotype structure. However, it remains unclear whether these chromosomal rearrangements are an integral component and driving force of the speciation process or they are established later, after speciation is completed. Further investigations of additional species, combined with molecular phylogeny and fluorescent in situ hybridization (telomere and $18 \mathrm{~S}$ rDNA probes), are needed to shed more light on this issue.

\section{Acknowledgements}

We are grateful to Lu Liu and Ning Li for assistance in specimen collection. We also thank Qiong-Hua Gao and Wei Du for species identification. We express our special thanks to Lorenzo Peruzzi and Rodolpho Menezes for their valuable comments and suggestions in the revision of the manuscript. This study was funded by the National Natural Science Foundation of China (grant number 31672341) and the China Postdoctoral Science Foundation (grant number 2019M663830). 


\section{References}

Astuti G, Roma-Marzio F, Peruzzi L (2017) Traditional cytotaxonomic studies: can they still provide a solid basis in plant systematics? Flora Mediterranea 27: 91-98.

Atchley WR, Jackson RC (1970) Cytological observations on spermatogenesis in four species of Mecoptera. Canadian Journal of Genetics and Cytology 12(2): 264-272. https://doi. org/10.1139/g70-039

Ayala FJ, Coluzzi M (2005) Chromosome speciation: humans, Drosophila, and mosquitoes. Proceedings of the National Academy of Sciences of the United States of America 102(suppl. material 1): 6535-6542. https://doi.org/10.1073/pnas.0501847102

Bombarová M, Špakulová M, Kello M, Nguyen P, Bazsalovicsová E, Králová-Hromadová I (2015) Cytogenetics of Aspidogaster limacoides (Trematoda, Aspidogastrea): karyotype, spermatocyte division, and genome size. Parasitology Research 114(4): 1473-1483. https://doi.org/10.1007/s00436-015-4330-5

Bornemissza GF (1966) Observations on the hunting and mating behaviours of two species of scorpion flies (Bittacidae: Mecoptera). Australian Journal of Zoology 14(3): 371-382. https://doi.org/10.1071/ZO9660371

Brown JD, O’Neill RJ (2010) Chromosomes, conflict, and epigenetics: chromosomal speciation revisited. Annual Review of Genomics and Human Genetics 11: 291-316. https:// doi.org/10.1146/annurev-genom-082509-141554

Bush GL (1966) The comparative cytology of the Choristidae and Nannochoristidae (Mecoptera). American Philosophical Society Yearbook 1966: 326-328

Butlin RK (2005) Recombination and speciation. Molecular Ecology 14(9): 2621-2635. https://doi.org/10.1111/j.1365-294X.2005.02617.x

Byers GW, Thornhill R (1983) Biology of the Mecoptera. Annual Review of Entomology 28: 203-228. https://doi.org/10.1146/annurev.en.28.010183.001223

Cabral-de-Mello DC, Moura RC, Martins C (2011) Cytogenetic mapping of rRNAs and histone $\mathrm{H} 3$ genes in 14 species of Dichotomius (Coleoptera, Scarabaeidae, Scarabaeinae) beetles. Cytogenetic and Genome Research 134: 127-135. https://doi. org/10.1159/000326803

Cardoso DC, das Graças Pompolo S, Cristiano MP, Tavares MG (2014) The role of fusion in ant chromosome evolution: insights from cytogenetic analysis using a molecular phylogenetic approach in the genus Mycetophylax. PLoS ONE 9(1): e87473. https://doi.org/10.1371/ journal.pone.0087473

Castillo ERD, Martí DA, Maronna MM, Scattolini MC, Cabral-de-Mello DC, Cigliano MM (2019) Chromosome evolution and phylogeny in Ronderosia (Orthoptera, Acrididae, Melanoplinae): clues of survivors to the challenge of sympatry? Systematic Entomology 44(1): 61-74. https://doi.org/10.1111/syen.12317

Chen J, Tan J-L, Hua B-Z (2013) Review of the Chinese Bittacus (Mecoptera: Bittacidae) with descriptions of three new species. Journal of Natural History 47(21-22): 1463-1480. https://doi.org/10.1080/00222933.2012.763065

Coghlan A, Eichler EE, Oliver SG, Paterson AH, Stein L (2005) Chromosome evolution in eukaryotes: a multi-kingdom perspective. Trends in Genetics 21(12): 673-682. https://doi. org/10.1016/j.tig.2005.09.009 
Cooper KW (1951) Compound sex chromosomes with anaphasic precocity in the male mecopteran, Boreus brumalis Fitch. Journal of Morphology 89(1): 37-57. https://doi. org/10.1002/jmor.1050890104

Cooper KW (1974) Sexual biology, chromosomes, development, life histories and parasites of Boreus, especially of B. notoperates. A southern California Boreus. II. (Mecoptera: Boreidae). Psyche 81: 84-120. https://doi.org/10.1155/1974/48245

Dincă V, Lukhtanov VA, Talavera G, Vila R (2011) Unexpected layers of cryptic diversity in wood white Leptidea butterflies. Nature Communications 2: 324. https://doi.org/10.1038/ ncomms 1329

Dutrillaux A-M, Dutrillaux B (2019) Different behaviour of C-banded peri-centromeric heterochromatin between sex chromosomes and autosomes in polyphagan beetles. Comparative Cytogenetics 13(2): 179-192. https://doi.org/10.3897/CompCytogen.v13i2.34746

Faria R, Navarro A (2010) Chromosomal speciation revisited: rearranging theory with pieces of evidence. Trends in Ecology \& Evolution 25(11): 660-669. https://doi.org/10.1016/j. tree.2010.07.008

Gokhman VE, Kuznetsova VG (2006) Comparative insect karyology: current state and applications. Entomological Review 86(3):352-368. https://doi.org/10.1134/S0013873806030110

Imai HT, Maruyama T, Gojobori T, Inoue Y, Crozier RH (1986) Theoretical bases for karyotype evolution. 1. The minimum-interaction hypothesis. The American Naturalist 128(6): 900-920. https://doi.org/10.1086/284612

Imai HT, Satta Y, Takahata N (2001) Integrative study on chromosome evolution of mammals, ants and wasps based on the minimum interaction theory. Journal of Theoretical Biology 210(4): 475-497. https://doi.org/10.1006/jtbi.2001.2327

Imai HT, Taylor RW, Crosland MW, Crozier RH (1988) Modes of spontaneous chromosomal mutation and karyotype evolution in ants with reference to the minimum interaction hypothesis. The Japanese Journal of Genetics 63(2): 159-185. https://doi.org/10.1266/jjg.63.159

Imai HT, Taylor RW, Crozier RH (1994) Experimental bases for the minimum interaction theory. I. Chromosome evolution in ants of the Myrmecia pilosula species complex (Hymenoptera: Formicidae: Myrmeciinae). The Japanese Journal of Genetics 69(2): 137-182. https://doi.org/10.1266/jjg.69.137

Kandul NP, Lukhtanov VA, Pierce NE (2007) Karyotypic diversity and speciation in Agrodiaetus butterflies. Evolution 61(3): 546-559. https://doi.org/10.1111/j.1558-5646.2007.00046.x

Kirkpatrick M (2010) How and why chromosome inversions evolve. PLoS Biology 8(9): e1000501. https://doi.org/10.1371/journal.pbio.1000501

Kociński M, Grzywacz B, Chobanov D, Warchałowska-Śliwa E (2018) New insights into the karyotype evolution of the genus Gampsocleis (Orthoptera, Tettigoniinae, Gampsocleidini). Comparative Cytogenetics 12(4): 529-538. https://doi.org/10.3897/CompCytogen.v12i4.29574

Lambkin KJ (1988) An Australian species of the genus Bittacus Latreille (Mecoptera: Bittacidae). Memoirs of the Queensland Museum 25(2): 439-444. https://biodiversitylibrary. org/page/43242356

Levan A, Fredga K, Sandberg AA (1964) Nomenclature for centromeric position on chromosomes. Hereditas 52(2): 201-220. https://doi.org/10.1111/j.1601-5223.1964.tb01953.x

Li Y-L, Ren D (2009) History and development of researches on Bittacidae (Insecta: Mecoptera). Acta Geoscientica Sinica 30(4): 554-560. 
Lukhtanov VA, Kandul NP, Plotkin JB, Dantchenko AV, Haig D, Pierce NE (2005) Reinforcement of pre-zygotic isolation and karyotype evolution in Agrodiaetus butterflies. Nature 436(7049): 385-389. https://doi.org/10.1038/nature03704

Lysak MA, Berr A, Pecinka A, Schmidt R, McBreen K, Schubert I (2006) Mechanisms of chromosome number reduction in Arabidopsis thaliana and related Brassicaceae species. Proceedings of the National Academy of Sciences of the United States of America 103(13): 5224-5229. https://doi.org/10.1073/pnas.0510791103

Ma N, Huang J, Hua B-Z (2014) Fine structure and functional morphology of the mouthparts of Bittacus planus and Terrobittacus implicatus (Insecta: Mecoptera: Bittacidae). Zoologischer Anzeiger 253(6): 441-448. https://doi.org/10.1016/j.jcz.2014.05.001

Matthey R (1950) La formule chromosomique et le type de digamétie chez Bittacus italicus Müll. (Mecoptera). Archiv der Julius-Klaus-Stiftung für Vererbungs Forschung 25: 605-611

Menezes RST, Gazoni T, Costa MA (2019) Cytogenetics of warrior wasps (Vespidae: Synoeca) reveals intense evolutionary dynamics of ribosomal DNA clusters and an unprecedented number of microchromosomes in Hymenoptera. Biological Journal of the Linnean Society 126(4): 925-935. https://doi.org/10.1093/biolinnean/bly210

Miao Y, Hua B-Z (2017) Cytogenetic comparison between Terrobittacus implicatus and Bittacus planus (Mecoptera: Bittacidae) with some phylogenetic implications. Arthropod Systematics \& Phylogeny 75(2): 175-183. http://www.senckenberg.de/files/content/forschung/publikationen/arthropodsystematics/asp_75_2/01_asp_75_2_miao_175-183.pdf

Miao Y, Hua B-Z (2019) Chromosomal characteristics of the hangingfly Bittacus flavidus Huang $\&$ Hua (Mecoptera: Bittacidae) and their phylogenetic implications. Acta Entomologica Sinica 62(6): 732-742. https://doi.org/10.1007/s00709-019-01415-w

Miao Y, Ma N, Hua B-Z (2017) Cytotaxonomy and molecular phylogeny of the genus Cerapanorpa Gao, Ma \& Hua, 2016 (Mecoptera: Panorpidae). Scientific Reports 7: 4493. https://doi.org/10.1038/s41598-017-04926-9

Miao Y, Wang J-S, Hua B-Z (2019) Molecular phylogeny of the scorpionflies Panorpidae (Insecta: Mecoptera) and chromosomal evolution. Cladistics 35: 385-400. https://doi. org/10.1111/cla.12357

Mills PJ, Cook LG (2014) Rapid chromosomal evolution in a morphologically cryptic radiation. Molecular Phylogenetics and Evolution 77: 126-135. https://doi.org/10.1016/j. ympev.2014.03.015

Navarro A, Barton NH (2003) Accumulating postzygotic isolation genes in parapatry: a new twist on chromosomal speciation. Evolution 57(3): 447-459. https://doi. org/10.1111/j.0014-3820.2003.tb01537.x

Naville A, Beaumont J (1934) Les chromosomes des Panorpes. Bulletin Biologique de la France et de la Belgique 68: 98-107

Nie W-H, Wang J-H, Su W-T, Wang Y-X, Yang F-T (2009) Chromosomal rearrangements underlying karyotype differences between Chinese pangolin (Manis pentadactyla) and Malayan pangolin (Manis javanica) revealed by chromosome painting. Chromosome Research 17(3): 321-329. https://doi.org/10.1007/s10577-009-9027-0

Nokkala C, Kuznetsova VG, Rinne V, Nokkala S (2019) Description of two new species of the genus Cacopsylla Ossiannilsson, 1970 (Hemiptera, Psylloidea) from northern Fennoscandia 
recognized by morphology, cytogenetic characters and COI barcode sequence. Comparative Cytogenetics 13(4): 367-382. https://doi.org/10.3897/CompCytogen.v13i4.47395

Noor MAF, Garfield DA, Schaeffer SW, Machado CA (2007) Divergence between the Drosophila pseudoobscura and $D$. persimilis genome sequences in relation to chromosomal inversions. Genetics 177(3): 1417-1428. https://doi.org/10.1534/genetics.107.070672

Paszko B (2006) A critical review and a new proposal of karyotype asymmetry indices. Plant Systematics and Evolution 258(1): 39-48. https://doi.org/10.1007/s00606-005-0389-2

Penny ND (1975) Evolution of the extant Mecoptera. Journal of the Kansas Entomological Society 48(3): 331-350

Penny ND (2006) A review of our knowledge of California Mecoptera. Proceedings of the California Academy of Sciences 57(9): 365-372

Penny ND, Byers GW (1979) A check-list of the Mecoptera of the world. Acta Amazonica 9(2): 365-388. https://doi.org/10.1590/1809-43921979092365

Pereira TTP, Reis ACCC, Cardoso DC, Cristiano MP (2018) Molecular phylogenetic reconstruction and localization of the (TTAGG)n telomeric repeats in the chromosomes of Acromyrmex striatus (Roger, 1863) suggests a lower ancestral karyotype for leafcutter ants (Hymenoptera). Comparative Cytogenetics 12(1): 13-26. https://doi.org/10.3897/CompCytogen.v12i1.21799

Peruzzi L, Eroğlu HE (2013) Karyotype asymmetry: again, how to measure and what to measure? Comparative Cytogenetics 7(1): 1-9. https://doi.org/10.3897/compcytogen.v7i1.4431

Rebagliati PJ, Papeschi AG, Mola LM (2003) Meiosis and fluorescent banding in Edessa meditabunda and E. rufomarginata (Heteroptera: Pentatomidae: Edessinae). European Journal of Entomology 100(1): 11-18. https://doi.org/10.14411/eje.2003.002

Rieseberg LH, Burke JM (2001) A genic view of species integration. Journal of Evolutionary Biology 14(6): 883-886. https://doi.org/10.1046/j.1420-9101.2001.00339.x

Stebbins GL (1971) Chromosomal Evolution in Higher Plants. Edward Arnold, London, 216 pp.

Stoianova D, Simov N, Vu MQ, Nguyen DM, Grozeva S (2020) New data on karyotype, spermatogenesis and ovarian trophocyte ploidy in three aquatic bug species of the families Naucoridae, Notonectidae, and Belostomatidae (Nepomorpha, Heteroptera). Comparative Cytogenetics 14(1): 139-156. https://doi.org/10.3897/CompCytogen.v14i1.48709

Tan J-L, Hua B-Z (2008) Structure of raptorial legs in Bittacus (Mecoptera : Bittacidae). Acta Entomologica Sinica 51(7): 745-752. http://www.insect.org.cn/EN/Y2008/V51/I7/745

Thornhill R (1977) The comparative predatory and sexual behavior of hangingflies (Mecoptera: Bittacidae). Occasional Papers of the Museum of Zoology University of Michigan 677: 1-43. http://deepblue.lib.umich.edu/bitstream/2027.42/57113/1/OP677.pdf

Ullerich FH (1961) Achiasmatische spermatogenese bei der skorpionsfliege Panorpa (Mecoptera). Chromosoma 12(1): 215-232. https://doi.org/10.1007/BF00328920

Ventura K, O’Brien PCM, Yonenaga-Yassuda Y, Ferguson-Smith MA (2009) Chromosome homologies of the highly rearranged karyotypes of four Akodon species (Rodentia, Cricetidae) resolved by reciprocal chromosome painting: the evolution of the lowest diploid number in rodents. Chromosome Research 17(8): 1063-1078. https://doi.org/10.1007/ s10577-009-9083-5

White MJD (1974) Genetic Mechanisms of Speciation in Insects. Springer, Dordrecht, 170 pp. https://doi.org/10.1007/978-94-010-2248-4 
Xu B, Li Y-K, Hua B-Z (2013) A chromosomal investigation of four species of Chinese Panorpidae (Insecta, Mecoptera). Comparative Cytogenetics 7(3): 229-239. https://doi. org/10.3897/compcytogen.v7i3.5500

Zhang Y-N, Du W, Hua B-Z (2020) Three new species of the genus Bittacus Latreille, 1805 (Mecoptera: Bittacidae), with a key to the species of Bittacidae in South China. Zootaxa 4718(3): 381-390. https://doi.org/10.11646/zootaxa.4718.3.6 